\title{
Visual evoked potential diagnosis of field defects in patients with chiasmatic and retrochiasmatic lesions
}

\author{
MARCO ONOFRJ, * IVAN BODIS-WOLLNER, ${ }^{*} \dagger$ LELAND MYLIN,* \\ From the Departments of Neurology* and Ophthalmology, $\dagger$ Mount Sinai School of Medicine, New York, \\ USA
}

SUMMARY Visual evoked potentials were studied in 18 patients with visual field defects assessed by perimetry. Stimuli were reversing checkerboard and grating patterns of 13', full field and hemifield. Two reversal rates were studied: $1 \mathrm{~Hz}$ (transient VEPs) and $8 \mathrm{~Hz}$ (steady-state VEPs). Using monocular hemifield stimulation the "paradoxical lateralisation" of transient but not of steady-state VEPs was confirmed. Diagnostic yield was $90 \%$ using transient, but less than $20 \%$ using steady-state stimuli.

Pattern evoked potentials (EPs) have proven to be more reliable than flash EPs ${ }^{1}$ in the clinical evaluation of the visual pathways. Commonly, "alternating" presentation is used, employing a modulation rate below $4 \mathrm{~Hz}$. The resulting "transient" $\mathrm{EP}^{2}$ waveform is a negative-positive-negative complex provided that the recording electrode is between the inion and $5 \mathrm{~cm}$ above, and the full field is stimulated. The precise latency and amplitude measurements of this EP depend on luminance, field size, spatial frequency, and contrast of the stimulus. ${ }^{3}$ The latency of the major positive wave is used most advantageously in the diagnostic evaluation of patients suspected of having multiple sclerosis.

Various studies have attempted to describe more accurately the transient VEP and to locate the source of its specific "components" by mapping the topographic distribution of the responses to hemifield or quadrant stimuli.4-17 Most authors agree that the major positive component appears over electrodes ipsilateral but not contralateral to the stimulated field. 4 810-13 This ipsilateral preponderance was called "paradoxical" since, due to chiasmal crossing of the pathways, one could expect it to be most prominent contralaterally. An attractive explanation is that "the cortical generator areas for the pattern stimulus are largely situated on the medial and posteromedial surface of the vidual cortex, where neurons are transversely oriented. Thus, electrodes

Address for reprint requests: Ivan Bodis-Wollner MD, 1200 Fifth Avenue, New York, NY 10029, USA.

Received 20 May 1981 and in revised form 15 October 1981 Accepted 1 November 1981 over the hemisphere ipsilateral to the field stimulated are optimally placed to record the responses" from the generator areas of the contralateral hemisphere. ${ }^{8}$

Understanding the normal distribution of VEP components is a prerequisite of using VEP methods to evaluate possible visual field defects. Indeed, since the description of this paradoxical distribution of the VEP, several studies have attempted to relate evoked potential changes in patients to visual field defects demonstrated by perimetry. This led to further controversies: using full field monocular stimulation and recording from a horizontal electrode array in normal subjects, the response has the same polarity in all the electrodes of the horizontal line, while an asymmetrical or completely inverted response is recorded from electrodes placed on the skull on the same side as the field defect. Others who also used pattern reversal stimuli in patients with field defects could not find this "paradoxically" altered response. 2021 Often, however, the precise stimulus conditions, such as pattern element size and reversal rate, were not taken into account. We report a study using both transient and steadystate EP evaluation in 18 patients referred for VEP testing and suspected of having a field defect. At the time of the VEP recording and data analysis, no information was available concerning the results of campimetry; thus the interpretation of the VEPs was not biased. The results obtained in patients with defects in their visual fields are compared to the data obtained in 22 subjects with normal visual fields. Secondly, we compare the results obtained using different methods of VEP stimulation in individual patients whose campimetric studies revealed field defects. 


\section{Methods}

The stimuli were checkerboard patterns of which each element in the diameter subtended 13 minutes of arc at the eye, and vertical gratings whose spatial frequency was $2 \cdot 3$ cycles/degree. Contrast was $50 \%$ for checks, $55 \%$ for gratings. While the checkerboard presented sharp contours, the gratings had a sinusoidal luminance profile. These patterns were generated using a method described elsewhere. ${ }^{22}{ }^{23}$ The stimuli were reversed twice per second $(1 \mathrm{~Hz}$ modulation rate) and 16 times per second $(8 \mathrm{~Hz}$ modulation rate), and presented either as full-field stimuli or as monocular hemifield stimuli. The screen was circular with a diameter of $14^{\circ}$ and hemifields were of half size. When hemifield stimuli were used, the unpatterned half of the screen had an average luminance identical to that of the first half. Space-time average luminance of all stimuli was $31.8 \mathrm{~cd} / \mathrm{m}^{2}$. The fixation point was central in full field stimuli, and $0 \cdot 1^{\circ}$ from the reversing patterns when hemifield stimuli were used. Scalp electrodes were placed $2.5 \mathrm{~cm}$ above the patient's inion, on the midline, and lateral electrodes at the same horizontal level, placed at $25 \%$ of the horizontally measured distance inion-nasion. The common reference electrode was in midfrontal position, ${ }^{411-1319}$ and a supplementary horizontal reference electrode was placed $2 \mathrm{~cm}$ above the mastoid process to evaluate the effect of possible electrode placement artifacts. The ground electrode was placed on the forehead. Impedance was below $5 \mathrm{k} \Omega$. The signal effecting the reversal of checkerboard and gratings triggered a Nicolet 1070 signal averager, which received potentials differentially amplified with Grass 5P5 preamplifiers and filtered with corner frequencies of $0 \cdot 15$ to $100 \mathrm{~Hz}$ with interposition of a 60 $\mathrm{Hz}$ notch filter. The averager was set for 128,256 , or occasionally up to 512 runs.

\section{Measurements}

First, the latency of the major positive wave of the transient VEP was measured over midline electrodes and evaluated as being normal or abnormal based on the ellipse representing distribution of latencies in the normal population. ${ }^{22}{ }^{23}$ Second, the latencies of the other components of the triphasic complex, typical of pattern $V{ }^{2}{ }^{8}{ }^{8}$ were measured. Third, the VEPs recorded from the lateral electrodes were inspected and compared to VEPs recorded from midline electrodes. The symmetry or asymmetry of distribution of the VEP in lateral electrodes was considered by evaluating mainly the polarity of the triphasic complex. The amplitude of the major positive wave was measured from the preceding negative component. It was considered only to assess the variability in normals.

The same steps were followed in the evaluation of the VEPs obtained using hemifield stimuli, with the aim of detecting the asymmetry of pattern VEPs in electrodes contralateral to the stimulating field, described by others, ${ }^{8}$ and its eventual variations. For steady-state EPs, the presence or absence of the quasi-sinusoidal response evoked by each reversal ${ }^{24}$ was evaluated in central and lateral electrodes, and the relative phase differences over the array of electrodes were measured. Phase measure- ments were based on a technique described by Regan. ${ }^{24}$

Patients

Of the 18 patients, two had suprasellar tumours, one had an intrasellar neoplasm, seven suffered from ischaemic insult to one of the occipital lobes, three had parietal lobe surgery for vascular anomalies, two had infiltrating tumours of the diencephalon, and one of the parietooccipital area. Two had extended demyelinating plaques in the occipital area. All the lesions were shown by CT scans and/or angiographic and pneumoencephalographic studies. All the patients had full field and hemifield stimulation of either eye with $1 \mathrm{~Hz}$ modulation rate (transient VEP). Ten of these patients were studied using both gratings and checkerboards. Fifteen patients had full field stimulation at $8 \mathrm{~Hz}$ modulation rate, with grating patterns. In three patients binocular stimulation was also studied.

\section{Controls}

Twenty-two subjects with normal visual fields were studied. Of these, five were normal subjects experienced in psychophysical testing, and the remaining subjects, affected by various systemic diseases not involving the visual pathway, had normal visual fields assessed by perimetry. All of the subjects had full field and hemifield stimulation of either eye with $1 \mathrm{~Hz}$ grating pattern reversal, 10 also with checkerboard pattern reversal and 15 with $8 \mathrm{~Hz}$ grating pattern reversal.

\section{Results}

\section{Normals}

In our normal subjects, VEPs to full field stimuli were symmetrically distributed over midline and lateral electrodes: the negative-positive-negative complex could be identified in all three electrodes in 13 of the 22 subjects $(59 \%)$. In some subjects bilateral asymmetries were recorded and compared to the midline VEP. In two subjects, only the two negative waves of both (right and left) lateral derivations were comparable to the components of midline VEPs. In five subjects, only the positive wave was identifiable and of the same latency $( \pm 5 \mathrm{~ms})$ as the positive waves recorded over midline electrodes. Finally, in two subjects, only an early negative component followed by a sluggish positive wave was recorded from both lateral electrodes. When latencies of the various VEP "components" were compared in our normal subjects, the maximum latency difference between the major positive wave recorded from the three horizontal electrodes was less than $8 \mathrm{~ms}$ (for a sampling rate of 1,000 points per second). The same maximal latency difference held true for the other measurable components, even though in no case did two subsequent components show exactly the same latency shift. The amplitude of the early negativemajor positive deflection was always greater in midline derivations in comparison with lateral 
derivations. The ratio of midline to lateral electrode amplitude varied among subjects from 1.3 to $2 \cdot 4$. In any one subject, the maximum amplitude difference between lateral electrodes was $20 \%$.

The paradoxical lateralisation to ipsilateral electrodes of the response to hemifield stimuli (proposed repeatedly by Barret et al, ${ }^{8}$ Blumhardt and Halliday, ${ }^{13}$ and Arruga et al ${ }^{17}$ was essentially confirmed in our normal subjects. VEPs recorded from derivations ipsilateral to the stimulated field had components with latencies corresponding to the latencies of VEPs recorded from midline electrodes. VEPs recorded from electrodes contralateral to the stimulated field had components with latencies different

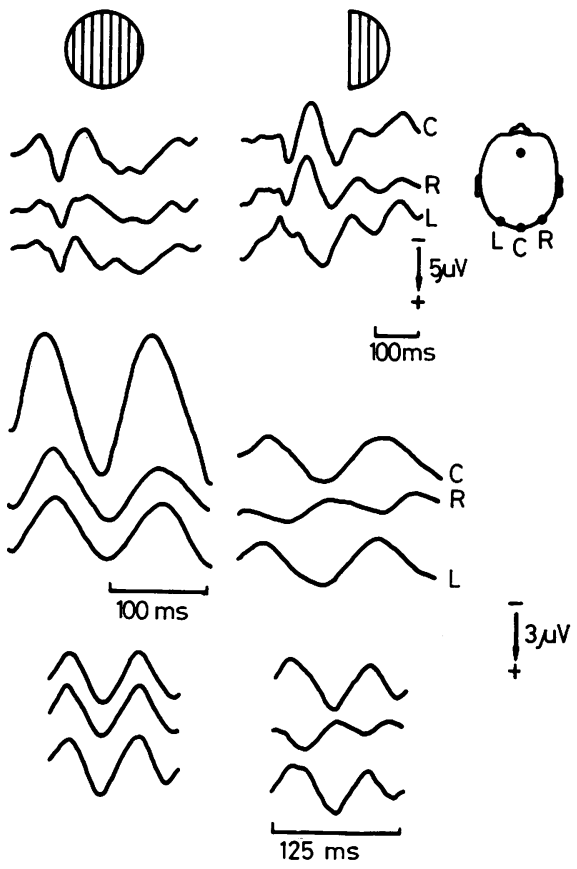

Fig 1 VEP traces to monocular stimulation in a normal subject are shown in sets of threes recorded simultaneously over $C$ (central), $R$ (right occipital), and L (left occipital) electrodes. Transient VEPs (top set of three traces, $1 \mathrm{~Hz}$ stimuli) and steady-state VEPs $(5 \mathrm{~Hz}$ stimuli, intermediate set of three traces and $8 \mathrm{~Hz}$ stimuli lower set) are shown. The same order of the traces $(C, R, L)$ $i$ followed in the lower set. On the left of the figure VEPs to full-field stimuli, on the right VEPs to right visual field stimuli are represented. Note that upon stimulating the right visual field symmetrical transient $V E P s$ are recorded from central and right electrodes, while a phase-shifted, abnormal looking transient VEP is recorded from the left electrode. Note that steady-state $V E P s$ show the opposite lateralisation (middle and lower sets of EP traces). from the latencies of VEPs recorded from midline electrodes (fig 1). These latency differences were attributed by other authors to two different topographical origins of the components, in relation to the retinal projections to visual areas. Even though the major positive wave is thought to reflect foveal pathway contribution, a paramacular origin for the contralateral positive-negative-positive complex and a macular origin for the ipsilateral negative-positivenegative complex (which includes the major positive component) has been assumed. ${ }^{13}$

The ipsilateral and midline components were an early negative component ( $N, 75-90$ ms latency), the major positive component ( $\mathrm{P}, 95-120 \mathrm{~ms})$, and a late negative component ( $\mathrm{N}, 120-180 \mathrm{~ms})$. Only modest latency differences $( \pm 6 \mathrm{~ms})$ were observed when the major positive component recorded from midline electrodes was compared in VEPs obtained with full field versus half field stimuli. The VEP components recorded from electrodes contralateral to the stimulated field were an early positive component (P, 65-90 ms), a negative component ( $\mathrm{N}, 102-135 \mathrm{~ms})$, and a late $P$ component (P, 130-160 ms). The comparison of VEPs recorded from ipsilateral, midline, and contralateral electrodes did not reveal a complete opposition of polarities of the NPN (midlineipsilateral) versus the PNP (contralateral) complexes. In four subjects the VEPs recorded on the contralateral channels were flat. The contralateral responses to hemified stimuli could be considered only partially inverted in polarity, never showing a complete $180^{\circ}$ phase reversal. We did not find complete phase reversal even when, in some patients, lateral electrodes were placed $20 \%$ further from the midline.

In eight subjects no lateralisation of the VEP to hemifield stimuli could be demonstrated for any one of the hemifield stimuli: VEPs of the same morphology were detected over ipsilateral, midline, and contralateral electrodes. All three electrodes showed grossly the same triphasic responses with normal latencies. This lack of lateralisation may well be due to poor fixation.

The amplitudes of the early negative-major positive deflection (recorded from ipsilateral and midline electrodes to the stimulating field) or of the P65-N102 deflection (recorded from contralateral electrodes) showed a variability of more than $50 \%$ in repeated recordings. The lateralisation of the steady-state responses to 5 and $8 \mathrm{~Hz}$ gave surprising results: while we found symmetrical distribution of the VEP in seven subjects, in the remaining eight normal subjects who participated in the study, when stimulating one hemifield, a high amplitude response was recorded from the central electrode and from the contralateral electrode, while no 
response or an attenuated $(40-70 \%) 180^{\circ}$ phase reversed response was obtained from the ipsilateral electrode (fig 1). Thus contralateral lateralisation of the steady-state, and ipsilateral lateralisation of the transient response, clearly are in agreement with the concept that transient and steady-state systems are not overlapping. ${ }^{24}$ Our findings were essentially similar to recently reported data of Kuroiwa and Celesia, ${ }^{19}$ even though they used a lower spatial frequency pattern $(0 \cdot 7$ cycles/degree) and a different reversal rate.

RESULTS IN PATIENTS WITH FIELD DEFECTS As revealed by campimetry, three patients had bitemporal hemianopias, 14 had homonymous hemianopias, and one had a left superior quadrantanopia. Analysis of the VEP led to the identification of a field defect in 17 of the 18 patients. In 15 of these 18 patients the field defect was diagnosed based on the evaluation of responses to full field stimuli, and then confirmed by responses to hemifield stimuli. In the remaining two patients a field defect had been suggested only after the interpretation of the responses to hemifield stimuli. Thus, using hemifield stimuli raised the diagnostic yield of VEPs from 83 to $94 \%$. In the patients with bitemporal hemianopia, full field stimuli were diagnostic: the electrodes ipsilateral to the temporal defect revealed inverted polarity responses in all (fig 2). These findings corresponded to the description of "crossed asymmetry". ${ }^{11}$ In one of these patients the asymmetry was found only using grating patterns while normal responses were evoked by checkerboard stimulation, and this discrepancy was confirmed in repeated studies (fig 3). Steady-state EPs to counterphase stimulation showed normal features in all these patients (fig 2). When using monocular temporal field stimuli in two patients, we repeatedly found a low amplitude response only in the central electrode, and in the electrode contralateral to the stimulating field but not over the ipsilateral electrode. This unusual finding represented an inversion of the "paradoxical" normal response. In the patient showing superior left quadrantanopia, normal VEPs were recorded both to full field and hemifield stimuli. In $12(80 \%)$ of the patients with homonymous hemianopia, the response to full field stimuli was clearly abnormal. In these patients asymmetrical VEPs were recorded from the electrodes ipsilateral to the field defect. These asymmetries were present during stimulation of either eye, and corresponded to the description of "uncrossed asymmetry".11 VEPs recorded from the electrodes ipsilateral to the field defect showed the emergence of the PNP complex (corresponding in normals only to contralateral hemifield stimulation), or only of a P135-150.
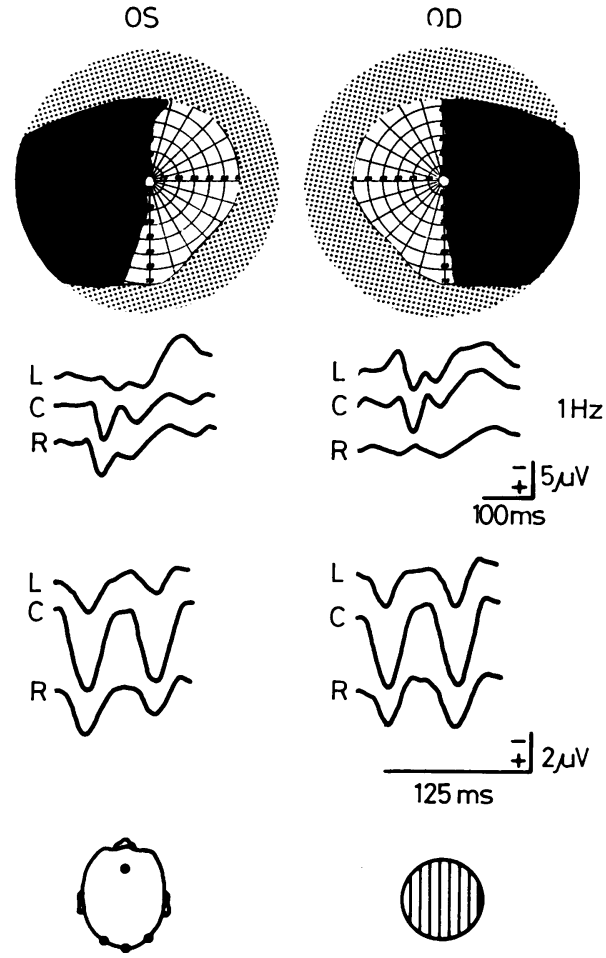

Fig 2 Perimetry charts of patient showing bitemporal hemianopia due to craniopharyngioma. The transient VEP shows a "crossed asymmetry", that is, when the left eye was stimulated with the grating pattern, a polarity inversion of the VEP was recorded from the electrode placed on the left, when the right eye was stimulated the polarity inversion of the VEP was recorded from right electrodes. $8 \mathrm{~Hz}$ stimuli gave normal responses.

No response at all was identifiable in three subjects from the electrode ipsilateral to the field defect. In two patients whose responses to full-field stimuli were normal, the responses to hemifield stimuli were abnormal. Also, in four of these patients with hemianopia, an inverted response with disappearance of the positive component was recorded over the electrode ipsilateral to the stimulated field using hemifield stimuli (fig 4). We shall discuss possible reasons for the emergence of a recordable (albeit normal) VEP when stimulating a "blind" field (fig 4).

While in five patients with homonymous hemianopias defective VEPs were recorded to full field stimuli in the electrodes corresponding to the hemianopia, in patients whose hemianopia was due to ischaemic insult of one of the occipital lobes (figs 5 and 6) the VEPs showed complex features. 

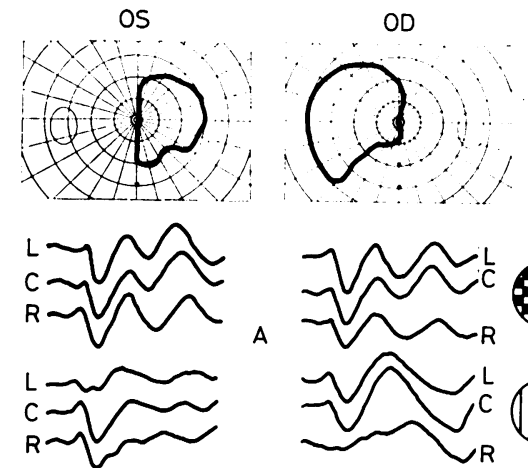

A
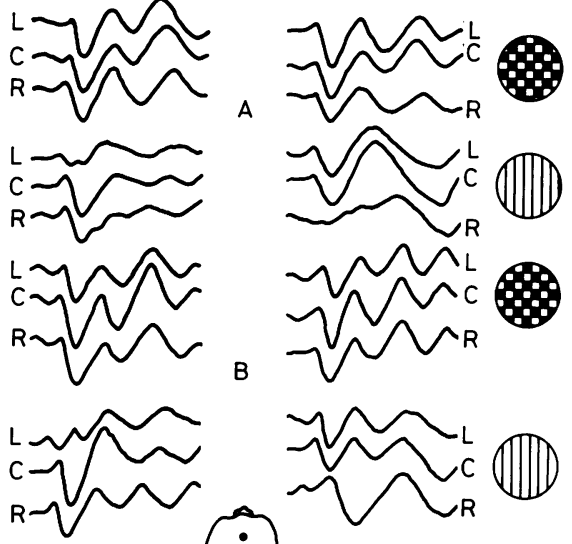

B

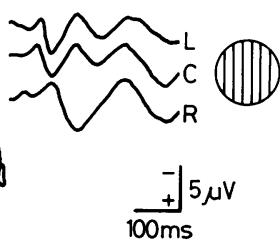

Fig 3 Bitemporal hemianopia due to craniopharyngioma. $V E P$ traces shown were recorded after surgery. Only the VEP to gratings but not to checks showed the "crossed asymmetry". A. Traces recorded 30 days following surgery. B. Traces recorded 8 months following surgery.

The major positive component was delayed in two of the seven patients $(28 \%)$. In three patients, binocular full field stimulation revealed a VEP asymmetry typical of a unilateral field defect (figs 5 and 6). Symmetrical VEPs were recorded when $8 \mathrm{~Hz}$ counterphase stimulation was applied. In one of the two patients, although binocular stimulation revealed a field defect, monocular transient stimulation failed to diagnose it: the VEP was markedly delayed but symmetrical over all electrodes (fig 5).

In two of the patients with homonymous hemianopias, steady-state responses were attenuated and phase shifted (fig 7) in the electrodes contralateral to the hemianopia. With respect to lateralisation, this is exactly the opposite to the results obtained in the same two patients using full field transient stimulation. In a third patient with left homonymous hemianopia, however, both transient and steady-rate responses lateralised to the right with respect to the paradoxical lateralisation of VEPs. The reasons for these discrepancies are not yet clear. Nevertheless it is apparent that transient and steady-state EP generators cannot be identical. In the table the

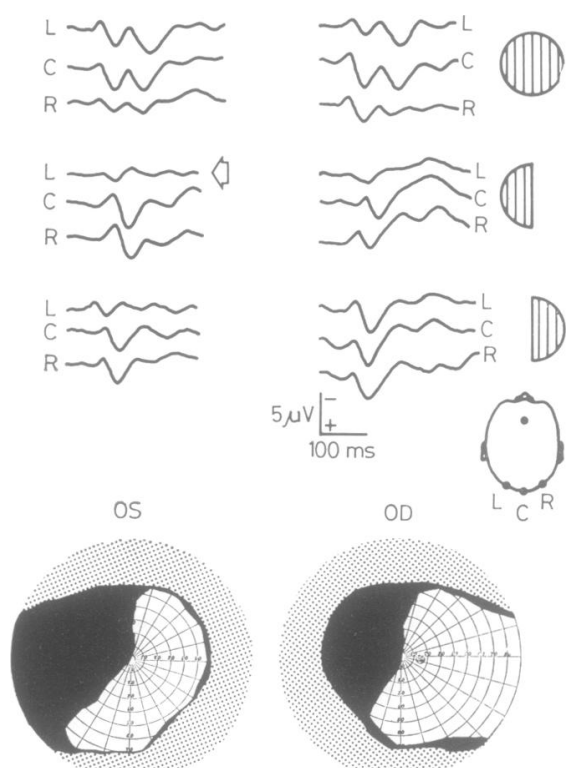

Fig 4 Partial left homonymous hemianopia following surgery for an arterio-venous malformation. Notice the normal response to full-field stimuli. There is no lateralisation evident in the responses to a right hemifield stimulus in the right eye. An arrow points to the anomalous reversal of the normal lateralisation of the response using a left-field stimulus. Notice the same anomaly in the traces recorded upon stimulating either eye. This anomalous lateralisation using hemifield stimuli is diagnostic of homonymous hemianopia (see text).

percentage diagnostic yield is summarised for each patient class and for each method used.

\section{Discussion}

Our data are in essential agreement with those of Halliday and his co-workers, in that the major positive component of the transient VEP to patterned stimuli is optimally recorded ipsilateral to the stimulated field. This paradoxical lateralisation was previously described for transient potentials evoked by low spatial frequency checks from 0.3 to 0.7 cycles/degree, 4810-131517-19 and our data suggest that somewhat higher spatial frequency gratings $(2 \cdot 3 \mathrm{c} / \mathrm{d})$ and checks also lateralise ipsilaterally. Steady-state EPs in normal subjects, however, show different features: they lateralise to the contralateral electrodes. Kuroiwa and Celesia ${ }^{19}$ recently reported similar data, using different checks and reversal rates. Apparently steady-state responses to hemifield stimuli have a different origin from transient 


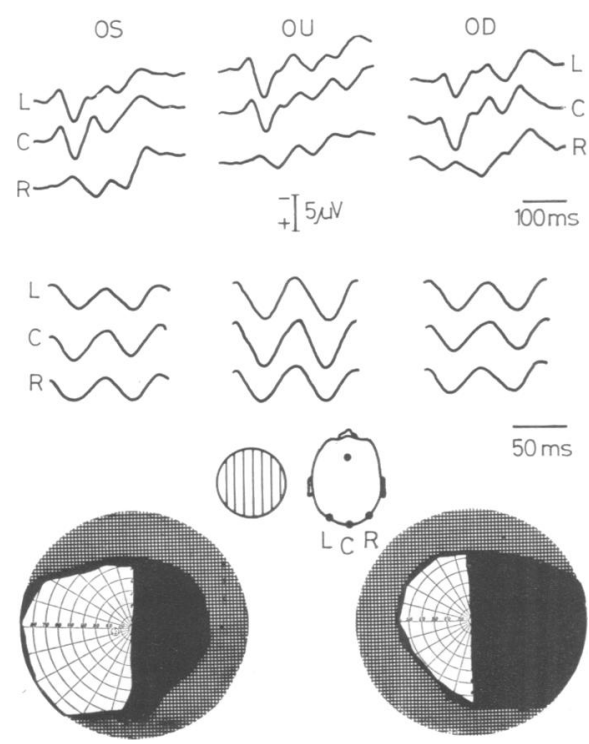

Fig 5 Perimetry charts showing right homonymous hemianopia due to cerebrovascular accident $(C V A)$, Shown are transient (top set of traces) and steady-state VEPs (bottom). Transient VEPs recorded from the right sided electrode show inverted polarities. The result was obtained using either monocular $(O D$ or $O S)$ or binocular $(O U)$ stimulation. Notice normal responses recorded to $8 \mathrm{~Hz}$ counterphase modulation.

responses. A further clinically important difference is that upon inspection, steady-state VEPs to counterphase modulation are less sensitive to field defects, and that when the steady-state EP is abnormal, it is not always contralateral to the field defect as would be expected from the data on lateralisation in normal subjects. These differences in transient and steady-state VEPs could in fact explain the controversy between Wildberger and his co workers ${ }^{20}$ and Halliday et al. ${ }^{111-13}$ Nevertheless, it is evident that a simple dipole model cannot account for both transient and steady-state data.

What is the clinically easiest, that is shortest, method to evaluate field defects using VEP techniques? Apparently, low rates of counterphase modulation are more useful. To avoid a lengthy test we recommend first the use of full-field stimuli and recording over central and lateral electrodes. An absent response or a polarity-inverted response (due to the emergence of the positive-negativepositive complex from one of the lateral electrodes) can indicate a field defect ipsilateral to the absent response. Fifteen of the 18 patients could be diagnosed as having a field defect using full-field stimuli (in one of these patients the response was abnormal

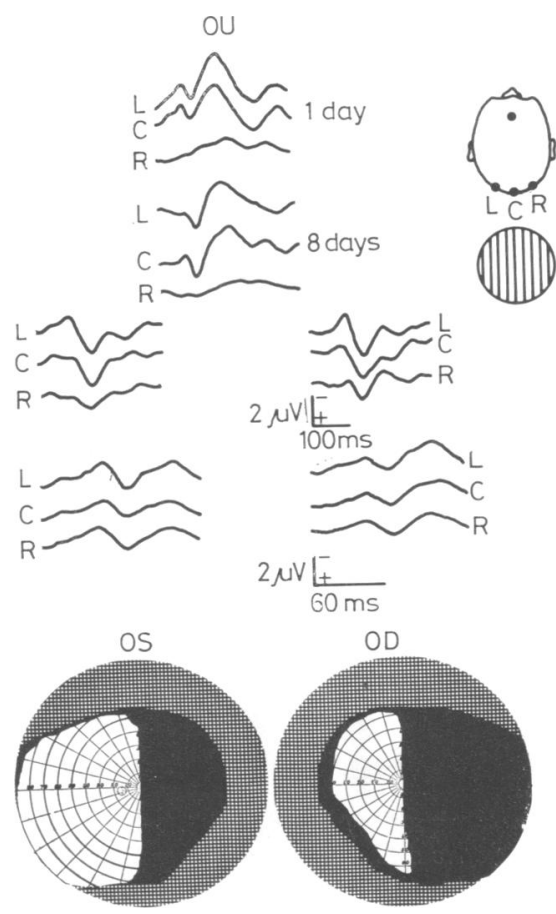

Fig 6 Perimetric charts show a right homonymous hemianopia due to a CVA. One day following the CVA, only responses to binocular stimulation could be recorded and the findings were conspicuous for a right field defect as shown. Eight days later, responses to binocular stimulation were still abnormal and confirmed the field defect. The VEP to monocular stimulation was delayed without any evidence of lateralisation corresponding to the field defect of the patient. Steady-state responses were low in amplitude, but did not reveal any lateralisation corresponding to the field defect.

only to gratings and not to checks (fig 3). Our impression is that full-field stimulation is mostly diagnostic when an extensive field defect is present and therefore if the full field VEP is normal, as a second step hemifield stimuli should be employed. Stimulating each hemifield separately in each eye revealed in 17 of 18 patients an absent response over the hemisphere ipsilateral to the field defect and in 12 of these the EP was absent in all derivations. It is probable that if a lesion causes only a peripheral visual field defect, the normal response of neurons supplied by macular fibres in the posteromedial surface of the occipital lobe will overwhelm the abnormal response of neurons responding to the periphery of the visual field with a minor cortical magnification coefficient. ${ }^{25}$ Further problems are raised by the analysis of responses to hemifield stimuli: while the 


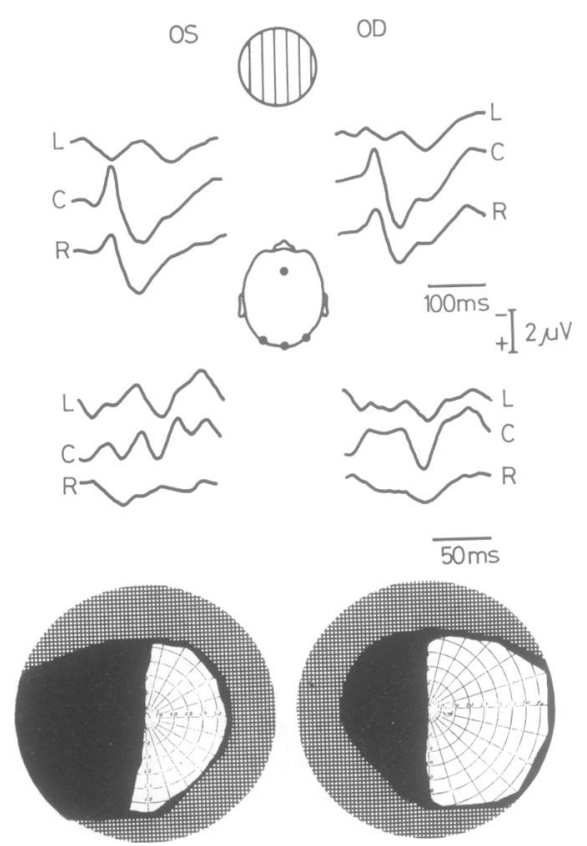

Fig 7 Perimetric charts showing left homonymous hemianopia in a patient with diencephalic tumour. Inverted polarity is evident in the transient VEP traces recorded from the left-sided electrode. Note opposite lateralisation of the VEP obtained using steady-state stimulation: normal polarity is evident in the recordings from left and central electrodes, while the $V E P$ recorded from the right-sided electrode is unidentifiable as a normal, quasi-sinusoidal response.

diagnostic yield can be enhanced we have to point out that we could demonstrate lateralised EPs to hemifield stimulation in only half of our untrained, relatively uncooperative normal subjects. In the others the EP was identical in all three derivations. We attribute this lack of lateralisation using hemifield stimuli to the vagaries of fixation since a random scanning of the stimulated field may be unavoidable, and in addition to the variations $\left( \pm 1^{\circ}\right)$ of the fixation point dependent on respiration and head position maintenance. ${ }^{26}$

It is possible that poor fixation explains why in four of our patients we found recordable EPs to hemifield stimuli over electrodes contralateral to the stimulated "blind" field and absent in the ipsilateral electrode (fig 4). Kuroiwa and Celesia ${ }^{19}$ recently reported a similar result, that is they recorded a "reversal of the normal pattern of transient VEP after stimulation of the affected hemifield" in patients with retrochiasmatic lesions. This finding could be explained by assuming that a recordable EP occurring from "blind" field stimulation represents subcortical responses. We do not think that this is necessarily so for the following reasons. In the primate, extrageniculostriate pathways diverge from the optic tract; thus chiasmal lesions should affect both cortical and subcortical pathways. But we found EPs from blind fields also in our patients with chiasmatic lesions, and thus EPs arising from blind fields cannot in each patient be attributed to subcortically generated signals. However, we cannot explain why in some patients there is a normal VEP to full field stimuli while hemifield stimulation produces an abnormality. This occurred in two of our patients and a similar result was reported by Kuroiwa and Celesia ${ }^{19}$ in some of their patients. Another explanation may be based on studies by others which suggest that some differences of the lateralisation of VEPs to hemifield stimuli are seen when macular or purely paramacular stimuli, with artificial central scotomata, are used. ${ }^{27}$

It is worth pondering the relationship of the aetiology of a field defect and VEP changes. VEPs recorded from midline electrodes had normal latencies in patients with field defects caused by chiasmatic lesion or retrochiasmatic lesions not of ischaemic etiology. In two of seven patients $(28 \%)$ whose field defect was caused by a cerebrovascular accident, delayed VEPs were recorded. This is similar to the percentage ( $25 \%$ ) observed by Kuroiwa and Celesia ${ }^{19}$ in their patients with retrochiasmatic lesions. However, we are not certain that these EPs are truly delayed. Based on our studies in the same patients using binocular and steady-state stimulation, we feel that what looks like a delayed VEP may be the result of distorted cortical electrogenesis due to laminar or parcellar lesions of the visual areas. In a recent article Blumhardt et al ${ }^{28}$ attribute to "wave-

Table Percent of the diagnostic yield of the VEP in 18 patients with field defects using a $2 \cdot 3$ c/d counterphase modulated grating pattern as the stimulus. The yield was similar using checkerboard patterns except in one patient with chiasmatic lesion who did not show any abnormality when checks were used

\begin{tabular}{|c|c|c|c|}
\hline & Full field stimuli & Full field + hemifield & Steady-state \\
\hline $\begin{array}{l}\text { All patients } \\
\text { Chiasmatic lesions } \\
\text { Retrochiasmatic lesions } \\
\text { not hypoxic } \\
\text { hypoxic aetiology }\end{array}$ & $\begin{array}{r}83 \% \\
100 \% \\
80 \% \\
75 \% \\
85 \%\end{array}$ & $\begin{array}{r}94 \% \\
100 \% \\
93 \% \\
87 \% \\
100 \%\end{array}$ & $\begin{array}{l}16 \% \\
20 \% \\
37 \% \\
-\end{array}$ \\
\hline
\end{tabular}


form distortions associated with amplitude changes" the modest "not significant delays" found in some of their patients affected by homonymous hemifield defects.

Although it is apparent that using pattern evoked potentials for the diagnosis of possible visual field defects one has to be meticulous about the precise stimulation methods and waveform indentification, the methods described may be useful in the neuroophthalmological evaluation. A VEP study may not rule out, but may detect a visual field defect.

This work was supported in part by grant No EY01708 of the National Eye Institute, NIH; grant No NS11631 of the Clinical Center for Research in Parkinson's and Allied Diseases; NIH Core Center Grant No EY01867, and NIH grant No RR-00071, Division of Research Resources, General Clinical Research Center Branch.

We thank Drs Michael C Barris and Phyllis Bobak for their collaboration in some of these studies, and Miss Caroline Leake, who prepared the artwork and typed the manuscript.

\section{References}

${ }^{1}$ Halliday AM, Mushin J. The visual evoked potential in neuroophthalmology. In: Sokol S, ed. Electrophysiology and Psychophysics: Their Use in Ophthalmic Diagnosis. International Ophthalmology Clinics. Boston: Little, Brown \& Co., 1980, Vol. 20, 155-83.

${ }^{2}$ Regan D. Recent advances in electrical recording from the human brain. Nature $1975: 253: 401-7$.

3 Jones R, Keck MJ. VER and grating spatial frequency. Invest Ophthalmol Vis Sci 1978:17:652-9.

${ }^{4}$ Halliday AM, Michael WF. Changes in pattern-evoked responses in man associated with the vertical and horizontal meridans of the visual field. $J$ Physiol (Lond) 1970:208:499-513.

${ }^{5}$ Cobb WA, Morton HB. Evoked potentials from the human scalp to visual half field stimulation. $J$ Physiol (Lond) 1970:208:39-40P.

${ }^{6}$ Jeffreys DA, Axford JG. Source locations of pattern specific components of human visual evoked potentials. Part 1. Components of striate cortical origin. Exp Brain Res 1972:16:1-21.

' Jeffreys DA, Axford JG. Source locations of patternspecific components of human visual evoked potentials. Part 2. Components of extrastriate cortical origin. Exp Brain Res 1972:16:22-40.

${ }^{8}$ Barrett G, Blumhardt AD, Halliday AM, Halliday E, Kriss A. A paradox in the lateralization of the visual evoked response. Nature 1976:261:253-5.

${ }^{9}$ Beauchamp M, Matthews WB, Small D, Stein JF. The topography of the visual evoked response to half field stimulation. J Physiol (Lond) 1976:260:46-47P.

${ }^{10}$ Shagass C, Amadeo M, Roemer RA. Spatial distribution of potentials evoked by half-field patternreversal and pattern onset stimuli. Electroencephalogr
Clin Neurophysiol 1976:41:609-22.

${ }^{11}$ Blumhardt LD, Barrett G, Halliday AM, Kriss A. The asymmetrical visual evoked potential to pattern reversal in one half field and its significance for the analysis of visual field defects. Br J Ophthalmol 1977: $61: 454-61$

${ }^{12}$ Halliday AM, Barrett G, Halliday E et al. The topography of the pattern-evoked potential. In: Desmedt JE, ed. Visual Evoked Potentials in Man: New Developments. Oxford: Clarendon Press, 1977: 121-33.

${ }^{13}$ Blumhardt LD, Halliday AM. Hemisphere contributions to the composition of the pattern-evoked potential waveform. Exp Brain Res 1979:36:53-69.

${ }^{14}$ Lesevre N, Joseph JP. Modifications of the patternevoked potential (PEP) in relation to the stimulated part of the visual field (clues for the most probable origin of each component). Electroencephalogr Clin Neurophysiol 1979:47:183-203.

15 Van Lith GHM, Henkes HE, Vijfvinkel-Bruinenga SM. Asymmetric pattern evoked responses and stimulus parameters. In: Schmoger E, Kelsey JH, eds. Visual Electrodiagnosis in Systemic Diseases, Vol 23, Doc Ophthalm Proc Series. The Hague, Netherlands: Dr W Junk, 1980:249-53.

${ }^{16}$ Lehmann D, Skrandies W. Visually evoked scalp potential fields in hemiretinal stimulation. In: Schmoger E, Kelsey JH, eds. Visual Electrodiagnosis in Systemic Diseases, Vol 23, Doc Ophthalm Proc Series. The Hague, Netherlands: Dr W Junk, 1980: 237-43.

17 Arruga J, Feldon SE, Hoyt WF, Aminoff MJ. Monocularly and binocularly evoked visual responses to patterned half-field stimulation. J Neurol Sci 1980: 46:281-90.

${ }^{18}$ Streletz LJ, Bae SH, Roeshmon RM, Schatz NJ, Savino PJ. Visual evoked potentials in occipital lobe lesions. Arch Neurol $1981: 38: 80-5$.

${ }^{19}$ Kuroiwa Y, Celesia GG. Visual evoked potential with hemifield pattern stimulation. Their use in the diagnosis of retrochiasmal lesions. Arch Neurol 1981 : 38:86-90.

20 Wildberger $\mathrm{HGH}$, Van Lith GHM, Wijngaarde R, Mak GTM. Visually evoked cortical potentials in the evaluation of homonymous and bitemporal visual field defects. Br J Ophthalmol 1976:60:273-8.

${ }^{21}$ Holder GE. The effects of chiasmal compression on the pattern visual evoked potential. Electroencephalogr Clin Neurophysiol $1978: 45: 278-80$.

22 Bodis-Wollner I, Yahr MD, Thornton J, Visual evoked potentials and the severity of Parkinson's disease. In: Rose FC, Capildeo R, eds. Research Progress in Parkinson's Disease. Tunbridge Wells: Pitman Medical, $1981: 126-37$.

${ }^{23}$ Bodis-Wollner I, Hendley CD, Mylin LH, Thornton J. Visual evoked potentials and the visuogram in multiple sclerosis. Ann Neurol $1979: 5: 40-7$.

${ }^{24}$ Regan D. Latencies of evoked potentials to flicker and to pattern speedily estimated by simultaneous stimulation method. Electroencephalogr Clin Neurophysiol 1976:40:654-60.

${ }^{25}$ Virsu V, Rovamo J. Visual resolution, contrast sensi- 
tivity, and the cortical magnification factor. Exp Brain Res 1979:37:475-94.

${ }^{26}$ Scott AB. Ocular motility. In: Record RE, ed. Physiology of the Human Eye and Visual System. New York: Harper \& Row Publishers, Inc., 1979:577-642.

${ }^{27}$ Blumhardt LD, Barrett G, Halliday AM, Kriss A. The effect of experimental "scotomata" on the ipsilateral and contralateral responses to pattern reversal in one half field. Electroencephalogr Clin Neurophysiol 1978: 45:376-92.

${ }^{28}$ Blumhardt LD, Barrett G, Kriss A, Halliday AM. The pattern evoked potentials in lesions of the posterior visual pathways. In: Bodis-Wollner I, ed. Evoked Potentials. Ann NY Acad Sci (in press). 